Revista Educación 27(2): 27-38, 2003

\title{
¡DEJAD QUE LAS DIFERENCIAS VENGAN A MÍ! UNIVERSIDAD Y EDUCACIÓN INCLUSIVA
}

\author{
Rolando Quesada Sancho ${ }^{1}$
}

Recibido 28-III-2003

Resumen: En este ensayo, expongo algunos aspectos que son necesarios en las universidades, para lograr una educación inclusiva. La educación inclusiva es una forma de mirar el horizonte que nos provee la convivencia a la luz del cumplimiento de los derechos humanos para la construcción de un mundo mejor. Las condiciones económicas, políticas, sociales y culturales obligan a pensar la educación desde una perspectiva con esperanza y posibilidad. No en vano los países miembros de las Naciones Unidas se han preocupado por tomar acuerdos que destierren de una vez por todas, cualquier viso de discriminación y segregación, sea cual sea la diferencia y han tomado esa diferencia como su estandarte, para plantear la urgencia de solidarizarse, convivir, ser tolerante y respetar al otro.

Esta diferencia puede ser cultural o individual, de ahí que la noción de "extranjero" adquiere mayor sentido en estos tiempos en que la acción humana tiende a segregar. De manera que pensar la diferencia como característica humana, abona en construir un mundo inclusivo. Esto nos obliga a mirar la educación prospectivamente, no para adivinar el futuro, sino para sacar a la superficie las fuerzas más importantes que impulsarán el futuro hacia una dirección. No se trata tampoco de construir en el vacío y dejar volar la inteligencia y la creatividad sin considerar las situaciones y tendencias sociales.

Aquí adquiere relevancia el hecho educativo, en tanto acción por la cual se produce, se reproduce, se resignifica, se transmite y se consume la cultura. En esta línea se plantea la necesidad por remozar los planes de estudio de las carreras formadoras de formadores y restaurar y estrechar el vínculo Universidad-Sociedad. De esta manera se propone como vía la observación constante que permita reflexionar en torno a su propio quehacer para modificarlo y crear nuevas condiciones que permitan atender la diferencia. Esta es una estrategia que permitirá a los estudiantes y a las estudiantes conocer las realidades nacionales y practicar la educación que necesita nuestra sociedad.

Palabras clave: Educación Universitaria, Prospección, Educación Inclusiva, Investigación.

\section{Introducción}

Pensar la universidad en los inicios de siglo es un reto grande; sin embargo, debe ser una tarea de todas las personas que reconstruimos el hecho educativo diariamente. Esto porque todo lo que suceda en el ámbito educativo nos concierne. Es por eso que consideramos conveniente que cualquier cambio, reforma o transformación que se proponga no debe pasar inadvertido ante nuestros ojos. En este sentido, debemos asumir la educación como un engranaje, donde un solo cambio en cualquier nivel afecta los otros y ellos, por supuesto, afectarán al cambio original.

Los cambios o reformas, teóricamente, son respuestas a necesidades identificadas, presentes y futuras, de manera que la prospección como componente sustancial de los cambios, se convierte en el motor que los dinamiza.

Visto de esa forma es válido tomar como referente algunos cambios sucedidos en la esfera mundial y las rutas que en lo local se van configurando. Dejar atrás la era geopolítica caracterizada por la polarización de la Guerra Fría manifestada tanto en los partidos políticos como en sindicatos, y que dominó los espacios universitarios y culturales durante los años de 1950 a 1980, promovió en su momento ajustes en la estructura económica, política, social y cultural de nuestro país. También dejamos atrás otra época comprendida entre los decenios de 
1980 al 2000, que se caracterizó por la crisis política, económica y teórica del bloque socialista y por el mercado mundial unificado, articulado bajo las premisas neoliberales conservadoras que vaticinaban el triunfo del sistema capitalista ortodoxo (Gorostiaga, 2000), cuya impronta la sobrevivimos en la actualidad.

Hoy, sin poder despojarnos de las consecuencias de la época anterior, nos encontramos en el quicio de una nueva, la neocultural que incluye los años que van del 2000 al 2020, en la cual se espera seguir trabajando algunos acuerdos, producto de las cumbres mundiales, organizadas por las Naciones Unidas (NN.UU.) en la década de los noventa, en las que se permitió que los gobiernos tuvieran que enfrentar, conjuntamente, los temas más acuciantes de la mundialización, a la vez que permitía que representantes de la sociedad civil mundial pudieran encontrarse y conformar redes globales sobre temas específicos. De manera que el consenso local y regional se fue aglutinando para fortalecer las redes de la sociedad civil y permitir a los organismos de las NN.UU. incorporar nuevos indicadores sobre desarrollo humano sostenible. Así se incluyen en los temas de trabajo, el medio ambiente, género, cultura y nuevas generaciones como ejes articuladores del desarrollo humano sostenible, “... pasando de la protesta sin propuesta de la fase geopolítica y neoeconómica a un movimiento de propuestas con protesta a veces, pero buscando una concertación, un pacto, un contrato social con otros actores para lograr un proceso de mejoría creciente de la viabilidad, gobernabilidad y sostenibilidad de la sociedad del futuro con dignidad y derechos para todos..." (Gorostiaga, Xavier; 44:2000). La incorporación de los elementos anotados y de los sujetos que los representan puede convertirse en un factor determinante, básico para establecer reformas para la transformación del sistema educativo, incluida la universidad pública.
Las NN.UU, por medio de la UNES$\mathrm{CO}$, ha propiciado al menos tres actividades sustanciales, que permitió la reunión de personas de la mayoría de los países del mundo, y conforman el referente cercano que lleva a reflexionar en los posibles avances locales en la temática de educación.

"La Conferencia Mundial de Educación para todos" realizada en 1990 en Jomtien, Tailandia, acordó la expansión de la asistencia y de las actividades de desarrollo de la primera infancia, incluidas intervenciones de la familia y la comunidad, especialmente para niños pobres, desasistidos e impedidos; acceso universal a la educación primaria; el mejoramiento de los resultados del aprendizaje; la reducción de la tasa de analfabetismo adulto mayor de 15 años para el año 2000; ampliación de los servicios de Educación Básica y de capacitación para los jóvenes y adultos; y el aumento de la adquisición de los conocimientos de las personas y de las familias, entre otros.

Cuatro años después, en 1994, se realizó en España "La Conferencia Mundial sobre Necesidades Educativas Especiales", en la cual “... se expusieron los principios, las políticas y las prácticas para responder a las necesidades educativas especiales de todas las personas dentro del sistema común de educación" y un marco de acción “... cuyo principio rector definió que todos los centros educativos debían acoger a todos los estudiantes, independientemente de sus condiciones, entre ellas la condición de discapacidad" (Navarrete; 1999:159).

Al iniciar este siglo, se efectúa el "Foro Mundial de Educación", en Dakar, Senegal, en el cual “...se propusieron respuestas a la falta de cumplimiento de los acuerdos mundiales anteriores, en el sentido de que la inclusión de personas con necesidades especiales o pertenecientes a minorías desfavorecidas, poblaciones migrantes, comunidades remotas y aisladas o tugurios urbanos, entre otros, deberán 
ser parte integrante de las estrategias para lograr la Educación para Todos, antes del año 2015" (CENAREC; 7:2002).

Por su parte, en el año 2001, los Ministros de Educación de Centroamérica, declaran reconocer a la diversidad como fundamento para la paz y el fortalecimiento de la democracia, donde las diferencias se comprendan como aporte y no como fuente de antagonismo ni de segregación, y se comprometen a seguir promoviendo la educación en general y la Educación Inclusiva en particular, como un derecho fundamental de la humanidad. (Fraternidad, nov. 2001).

Este escenario obliga a detenernos para preguntar: ¿cómo debemos interpretar esa visión de futuro que nos permita realizar las reestructuraciones pertinentes en los planes de estudio de la formación de formadores para atender la diversidad y aportar a consolidar la educación inclusiva?

Este ensayo tiene como propósito compartir algunas ideas que permitan despejar el tema, que no dudamos es de alta complejidad, y tiene varias rutas por las cuales se puede abordar. De manera que la reflexión comprende una aproximación a la noción de prospección, luego lo que podemos comprender como el "otro" cultural e individual, que nos permita entonces dibujar los sujetos y esa diversidad a la que se refieren los acuerdos antes expuestos, luego la responsabilidad de la universidad pública y la formación de formadores.

\section{La prospección como posibilidad}

La esperanza es la constructora de horizontes que son los que proveen de contenidos renovadores para resignificar las realidades. Esos horizontes son la aventura de asomarse a lo inédito y por lo tanto incierto y que se caracteriza por su pluralidad de posibilidades y por la ruptura con lo dado.
Pensar los horizontes también significa traspasar el límite y mirar aquello que contiene en su interior, pero a la vez aquello que lo trasciende que no es más que la génesis del horizonte, situación que contiene la capacidad de producir asombro.

"De ahí que el conocimiento es el asombro vuelto sobre sí mismo, mientras que el asombro es el conocimiento como capacidad de salirse de sí mismo para rastrear las incertidumbres y encontrar lo maravilloso vislumbrado para traerlo a la quietud de su constatación" (Zemelman; 167:1992b).

La educación inclusiva se asume como esperanza y posibilidad, y en ese sentido como una totalidad siempre en construcción, que tiñe la visión de mundo que poseemos. De ahí que, no solo es necesario sino urgente, instalar en las universidades prácticas educativas que asuman en forma cotidiana, la responsabilidad intelectual y ética de gestar realidades que se caractericen por su capacidad para articular contenidos teóricos con horizontes históricos y sus múltiples opciones de construcción. Sin embargo, no podemos obviar que obstáculos varios llegarán al encuentro, dado que existe un entramado conceptual y cultural que contiene a la mente y la mantiene en un estado perezoso.

Tales prácticas conforman un proceso prospectivo, que “... tiene como máximo interés el diseño de un escenario probable y de varios escenarios alternos. Puesto que el trabajo de los escenarios supone conocer las variables que los integran" (Mojica; 122:2000). Y, por tanto, podrían promover la trasgresión de los umbrales propuestos por la cultura de referencia u oficialista, para proponer nuevas alternativas. Estas rupturas plantean la construcción de una conciencia crítica.

La educación universitaria no debe darle la espalda a los acontecimientos promocionados por algunos organismos internacionales, para pensar la institución que se avecina. De modo que la educación superior 
del futuro debe ser una puerta de acceso al conocimiento, quizá la puerta más importante por su situación privilegiada para la generación y transmisión del saber humano (ANUIES, 1998).

En la reconfiguración de la sociedad, las universidades tradicionales coexistirán con otras que apenas llegan al escenario educativo, como es la universidad virtual, la universidad corporativa, u otras formas de estructura universitaria que hoy apenas se vislumbran.

Se requiere, entonces, que los actores sociales tengan una formación crítica y que estén informados, con posibilidades de externar y compartir libremente sus ideas, de manera que se debe compartir una formación en aquellos valores acordes con la sociedad de la cual se es parte, con un sentido de futuro social basado en la democracia, la libertad y la justicia social.

No en vano, el profesor Vázquez Gómez, de la Universidad Complutense de Madrid, citado por Benedito, Ferrer y Ferreres dice que la Universidad “... precisa de unos nuevos marcos que le permitan auto-organizarse para responder a las necesidades y a los cambios en las diferentes esferas políticas, sociales, económicas, laborales y tecnológicas". Sin embargo, quienes lo citan contra-argumentan que “... debería asumir aquel papel de liderazgo intelectual, crítico, científico que en diversos periodos históricos ha asumido" y, continúan diciendo que "La universidad debe volver a responsabilizarse de la sociedad de la que forma parte y asumir el protagonismo como motor cultural y social que le confiere el privilegio de sus características" (1995:33).

En esta misma línea podemos anotar conjuntamente con el chileno Hugo Zemelman, que “...lo desconocido no asume la forma de un enigma, sino que constituye un imperativo gnoseológico y volitivo para construir lo inédito. Ello supone no aceptar quedarse dentro de la estabilidad guarnecida por los límites; por el contrario, estamos obligados a embestirla en la búsqueda de una utopía como es la de la lucha por una conciencia protagónica, y así poder avanzar para enriquecer nuestra propia relación con la realidad, aprobada como ese horizonte que desafía como nuevo objeto a la voluntad consciente" (166:1992).

No podemos entonces permanecer separados de estas nuevas corrientes que dinamizan no solo la educación sino la sociedad en general. Específicamente lo referente a la universidad, pareciera que se debe encauzar a la búsqueda de otros modelos, y dejar atrás aquellos, cuya vigencia es incierta en tanto que tienden a ser insuficientes o porque favorecen a una élite y no al conjunto societal, que fundamenta su contrato originario.

El abandono de las categorías únicas para pensar el mundo, parece instalarse más como exigencia que como solicitud, esa racionalidad absoluta que muchas veces orientó el quehacer del ciudadano y de la ciudadana del siglo recién pasado, parece que ha entrado en franca decadencia. Los grupos organizados (pacifistas, ecologistas, feministas y lesbico-gays, entre otros) abogan por la interpretación de las realidades desde una perspectiva plural, con equidad e igualdad de oportunidades en el acceso a los bienes materiales y simbólicos. Esta crisis de la racionalidad cuestiona indudablemente el rol de la "universidad como regente-universal-del conocimiento, el saber, la técnica y las artes". (Benedito, Ferrer y Ferreres; 1995:32).

En un país como Costa Rica, que en las últimas décadas ha apostado al turismo y a los capitales "golondrina", donde la inmigración ha reconfigurado la composición social y cultural, y se acentúa la exclusión social y el interés por expulsar del escenario nacional lo poco que queda del Estado de Bienestar, se establecen pautas claras del estado actual y futuro cercano de las condiciones de vida que experimentaremos, mismas pautas deben ser criterios para revisitar la universidad pública. 
¿Cómo comprender las reconfiguraciones sociales que el presente depara para idear una educación que se oriente hacia la inclusión, y se despoje de una vez de cualquier forma de segregación?

\section{El escenario escolar}

Nuestras instituciones escolares se están poblando de estudiantes que provienen no solo del barrio, sino de múltiples lugares, algunos más cercanos que otros. Hemos pasado de tener una escuela con una población relativamente homogénea, para encontrarnos con una diversidad inédita, la cual, no estábamos preparados para atender.

Este nuevo poblamiento escolar nos lleva a repensar la lógica de la reconstrucción de las identidades internas. Recordemos que en todas las sociedades y en los grupos sociales que comparten espacios y tiempos determinados se narran las historias, los cambios y los conflictos, se reconstruyen mitos, ritos y estereotipos, con la finalidad de ir perfilando los rasgos de pertenencia a una nación o al grupo.

De modo que quienes comparten esas características se asumen como grupo, que ocupan un espacio determinado. Ellos y ellas han construido una identidad. Sin embargo, los movimientos sociales admiten, que de los grupos culturalmente ya constituidos, ingresen y salgan otras personas. Esta dinámica nos plantea una relación dialéctica, entre el "extranjero" entendido como las personas que llegan al grupo y el "nativo" como las personas que pertenecen al grupo. Ambas partes, extranjeros y nativos, después de un proceso muchas veces escabroso, modifican los bagajes identitarios iniciales para hibridizarse, y obtener nuevas y resignificadas prácticas culturales que las identificarán y los identificarán.

Entonces, cuando hablamos de "ser extranjero", no siempre significa que se pertenece a un lugar fuera de las fronteras de un determinado estado-nación, sino que esas fronteras son construcciones que se utilizan para cercar aquellos espacios simbólicos y objetivos, que deseamos sean pisados solo por "nosotros", lo que nos sirve para identificarnos y diferenciarnos de quienes se quedan fuera del cerco, que automáticamente se convierten en extranjeros.

Podemos pensar entonces que, tal como dan cuenta las experiencias identitarias, el "otro", que se incorpora a un espacio que no es el suyo, paulatinamente va dejando de ser extranjero, pero no tan fácil llega a ser nativo. Este proceso no es ni automático ni instrumental, por el contrario, está caracterizado por las pujas y las relaciones de poder entre las partes, de modo que no todos llegan a ser un "nosotros"; esto va a depender no solo de las características colectivas sino también de las individuales, que pueden promover la inclusión o la exclusión del grupo ya constituido. Así las características individuales, pueden significar un motivo para invisibilizar a las personas y asimilarlas a una extranjería.

No basta entonces con desear ser nativo y apropiarse de un espacio simbólico determinado, sino que es necesario ser asumido por el grupo nativo. Esto nos permite construir la "extranjería", ciertamente para referirnos a un "otro" con nacionalidad diferente, o al que viene llegando de otra provincia, de otro barrio, de otra escuela y hasta de otra aula de clase, que pretende asumirse como nativo, es decir, como del grupo. Pero también tratamos como extranjeros y extranjeras a quienes tienen diferencias individuales y las invisivilizamos, porque no son consideradas como "normales". Con esta acepción de extranjero nos referimos a mujeres, a negros y negras, a indígenas, a personas "gay" y lesbianas y a quienes tienen alguna discapacidad, entre otros, los que abonan al encasillamiento histórico como personas "no normales".

Debemos reconocer y celebrar que en la actualidad, nuestro territorio nacional y 
escolar, dichosamente está plagado de "extranjeros", que nos dan la posibilidad de mirar la vida como un vitral, un mundo multicolor y desarrollar con más solidez valores humanistas. Pero no siempre nos detenemos a esculcar la gran variedad de tonos de la vida cotidiana, que nos presentan esos vitrales.

Hoy podemos asegurar que la "otredad" tiende a colocarse en el vértice de la pirámide social, cultural y política. Son múltiples los factores intervinientes, que se han agudizado con los movimientos migratorios, tanto del interior a la capital como del exterior a nuestro país, producto de las crisis económicas y sociales, de las guerras, del narcotráfico, del agotamiento de las fronteras agrícolas, pero también por la reivindicación de algunos movimientos que han logrado la visibilización cada vez mayor y más frecuente, de grupos que históricamente habían permanecido marginados social y culturalmente.

Estas dinámicas están cambiando el escenario cotidiano y nos obligan a pensar las estructuras económicas, sociales, y culturales y obviamente el sistema educativo de otra manera.

Si echamos un vistazo a nuestras realidades educativas, nos encontramos con centros poblados por personas que ya no se identifican solo con Juan Santamaría como héroe nacional, que no comprenden muy bien la festividad del 25 de julio, o no saben correctamente la letra del himno nacional, pero sí conocen plenamente otros himnos nacionales, otras fiestas patrias, otros héroes, que los identifican con otros espacios que ya no habitan; también nos encontramos con personas con colores, tamaños, estilos, formas y con preferencias sexuales diferentes entre sí, (gay, lesbianas, heterosexuales), o que tienen formas de comunicarse y de participar que no son las convencionales. Ahí en esos y otros grupos estamos nosotros, etiquetando y etiquetados, para segregar y ser segregados. Lo que nos lleva a pensar que si queremos un mundo mejor, debemos propiciar una aceptación comprometida que nos permita reconstruir ese mundo, esa realidad que nos exigen los tiempos actuales.

Nosotros, personas que hemos llegado o que hasta ahora nos visibilizamos en los espacios educativos de nuestro país, configuramos conjuntamente con las nativas y visibles, el collage educativo que la educación debe atender, con el fin de construir todos una educación inclusiva, para todo ese collage al que nos hemos referido.

Entonces: ¿Cómo abrir los cercos educativos para que nadie se sienta extranjero en un espacio que le pertenece y al que tiene derecho? Estamos ante una situación que nos conduce a cambiar nuestra manera de ver el mundo, nuestra cosmovisión. Dicha reconfiguración debemos asumirla desde dos grandes instituciones: la familia y la escuela. Ellas constituyen las unidades básicas de producción, reproducción, distribución y consumo cultural. Allí se aprende y se aprehende aquello que nos acompañará en un gran trayecto de nuestras vidas.

\section{El escenario universitario actual}

No es un secreto que las universidades públicas tienden a alejarse cada vez más de su misión que socialmente deben cumplir y, en ese proceso, se han separado del compromiso social, para coquetear con el mercado, de manera que, con frecuencia, nos encontramos formando profesionales con una visión reactiva. Sin darnos cuenta nos desplazamos por la institución compitiendo con las universidades privadas, obviando de esa manera nuestro posicionamiento rector y nuestra responsabilidad propositiva en la sociedad costarricense.

Algunas unidades académicas se limitan a satisfacer las solicitudes del mercado y en esta lógica se van estableciendo fragmentaciones con la finalidad de ofertar novedades académicas cada vez más especializadas. 
La experiencia como asesor en temas curriculares reflejó la dificultad que se ha tenido para que algunas escuelas incorporen los temas de discapacidad, de género, de ecología, como ejes transversales en sus currículos, dificultad que deriva del interés por limpiar los planes de estudio, de aquellos temas que no son parte del paquete de saberes exclusivos de la disciplina, y porque según algunos y algunas docentes no se debe exigir a los estudiantes y a las estudiantes que conozcan temas que no son de la carrera, redundando entre otras cosas, en una segregación de discursos que generan las "minorías"; otros ejemplos se refieren al interés de algunas decanaturas y direcciones de unidades académicas por eliminar el trabajo comunal universitario, que supone un vínculo entre estudiantes y comunidad (que por cierto, algunos de ellos se encuentran bastante desvirtuados y hasta degradados). También los seminarios de realidad nacional y hasta los estudios generales han sido blanco de los intentos de eliminación. Esto no quiere decir que ellos deben permanecer tal cual se encuentran, requieren quizás un remozamiento con un mayor compromiso con los problemas nacionales.

Esta situación provee los elementos fundamentales para construir la realidad en forma fragmentada, que ha llevado a creer que la disciplina en la cual nos preparamos o nos hemos preparado actúa aisladamente de otras. Profesionales de una disciplina poco o nada conocen de otras. Por ejemplo, profesionales en salud no conocen para qué sirve y para qué le sirve a la medicina la antropología, algunos educadores y educadoras consideran que conocer acerca de la economía no es de su competencia, entre otros (Quesada y Monge; 2002).

También se puede anotar como parte de esta caracterización, la rigidez y la saturación de contenidos academicistas, de algunos planes de estudio, limitando así los análisis de los problemas nacionales y de articular su profesión con las necesidades sociales; así los espacios educativos se restringen a lo estrictamente académico, estableciendo una ruptura con la vida cotidiana.

Convengamos que muchas veces los planes de estudio son reestructurados por docentes que se han acomodado al sistema, y que no quieren ser perturbados con temáticas novedosas que los obliguen a actualizarse, configurando un grupo dominante que tamiza y decide los saberes que debe comprender la formación en una carrera determinada. De modo que quienes no hayan tenido acceso a esos grupos dominantes, no tienen oportunidad de participar en las tomas de decisión y, por lo tanto, no se van a ver representadas en los planes de estudio. En esta experiencia también podemos observar la lógica del nativo y del extranjero, cuyos discursos son segregados de las decisiones que se toman para configurar un plan de estudio. De esa forma la cotidianidad de las personas silenciadas seguirá ausente de las aulas de la universidad (Quesada; 2001).

Por eso consideramos que el diálogo con la sociedad puede estar debilitado, muchos trabajos comunales que mantenían un compromiso social, han sucumbido a las restricciones presupuestarias o, como dijimos, se han tergiversado. De modo que son escasas las estrategias de comunicación real que sobreviven a esta rigidez curricular. Con esto también se minimiza la creatividad como componente esencial del currículo.

La formación de formadores corre el mismo riesgo de caer en esa fragmentación: basta con observar la variedad de carreras en educación que ofrecen las universidades públicas. Los planes de estudio en general, tienen una estructura de cursos que no favorece una adecuada interrelación y articulación horizontal y vertical, para implementar nuevas pedagogías y didácticas. Esto puede promover la repetición de contenidos, condición que se asocia al desconocimiento por parte de algunas profesoras y profesores de la totalidad del plan de estudio ${ }^{1}$ de la carrera en la que imparten cursos, abriendo 
la posibilidad para que cada docente reproduzca, a su discreción, los conocimientos que considera que el estudiante y la estudiante debe poseer.

No debemos olvidar que los maestros y las maestras no solo reproducimos y enseñamos contenidos, sino que además transmitimos actitudes, creencias, prejuicios, ritos, entre otros, y que algunas de estas características transmisibles, fueron a su vez heredadas de los profesores y las profesoras universitarias, que a su vez las habían adquirido durante el paso como estudiantes, y que no siempre han coadyuvado a la atención de las diferencias. Al contrario, el enfoque pedagógico positivista que ha imperado e impera, parte del supuesto de la "normalidad", la homogenidad y la estandarización, por lo que la diversidad y la diferencia no tienen cabida. La pregunta obvia: ¿Cómo establecer rupturas con la cadena de producción reproducción y consumo cultural heredadas de profesores y profesoras, que nos permitan reinventar nuestro quehacer para atender la diversidad con una orientación inclusiva?

La respuesta en parte está en las transformaciones que podamos establecer en los planes de estudio de la formación de formadores, y propiciar reformas con el fin de promover una formación, que permita no solo observar sino vivir el vitral de nuestras realidades. Una reforma curricular, significa un cambio en cuanto a la forma de mirar, oler, sentir, el mundo y la de transformar el conocimiento y ser transformado por él. Es decir, es un proceso tanto cognitivo como político, que promueve el reemplazo de un escenario simbólico por otro, donde se establecen rupturas con aquello que se considere poco pertinente en relación con el profesional que demanda y necesita la sociedad. Esto decididamente solicita que las diferentes realidades, formen parte de las discusiones que se generan en la academia, y hace posible el ingreso de la diversidad en los espacios áulicos (Quesada; 2001).
Una reforma así planteada, como cambio en la cosmovisión de los sujetos hacedores de la educación, permitirá abrir espacios para formar profesores y profesoras críticas, que lleven en su interior la necesidad de transformar las prácticas educativas para atender la diversidad con la meta de construir una educación inclusiva.

Esto evidencia la necesidad de que las universidades públicas, y las facultades responsables de la formación de formadores, tomen la rectoría en la materia, con una visión propositiva, para evitar quedarse ancladas en la visión monocromática y homogenizada de la vida, y nos muestren, y nos ayuden a mostrar todos los colores que componen nuestra vida cotidiana. Incorporar los saberes de las personas silenciadas en los currículos universitarios, obliga a realizar un cambio paradigmático; ellas lo están demandando. La toma de conciencia acerca de la discapacidad, de la multiculturalidad, de la pobreza, de la exclusión, de los desastres ecológicos y la segregación, nos abona al reservorio de saberes necesarios para formar formadores con recursos simbólicos que les permitan científicamente atender la diversidad con miras a la reconfiguración de la educación, con una visión crítica.

\section{El escenario propuesto}

La situación descrita nos plantea una responsabilidad histórica, pues nos encontramos colocados frente a la urgencia de reeditar la educación, con base en la premisa de educación para todos y todas, con todos y todas y para cada uno y una.

Como docentes universitarios, debemos contemplar como exigencia social, la recopilación de las diferentes cosmovisiones, con el fin de que los múltiples grupos queden representados en las síntesis culturales que conforman el currículo. Los planes de estudio, deben entonces reflejar aquello suscrito en el currículo, y 
en él deben plasmarse no solo las voces de las personas que siempre han permanecido incluidas, sino también las -hasta ahoraexcluidas, para que de una vez por todas incluyamos y nos incluyan a la vez. Esto debe darse sin obviar las diferencias y las relaciones desiguales y asimétricas que rigen la vida cotidiana, no para legitimarlas sino para comprenderlas y transformarlas.

La necesidad de crear un plan de estudio, al menos en la formación de formadores, fundado en la unidad en la diversidad, que se caracterice por el respeto, el reconocimiento y solidaridad con la diversidad, con una visión de educación inclusiva, parece ser la vía que nos acerque a una verdadera reforma educativa, que nos permita ir a la búsqueda de una sociedad justa y que ella a su vez venga a nuestro encuentro, recorrido que no descartamos se haya comenzado, con los aportes de las reuniones internacionales y regionales anotadas al inicio.

En tanto personas con características culturales e individuales diferentes, lograríamos desplazarnos sin el temor a la diferencia, al contrario, esa diferencia sería el estandarte de la unidad.

Si queremos reconfigurar el escenario, debemos abordar algunos temas que hoy se instalan como exigencias, como: el deterioro ecológico, el incremento de la pobreza, la exclusión y la intolerancia a la diversidad, entre otros, que retardan el cumplimiento de la Declaración Universal de los Derechos Humanos. Estos ejes no se pueden abordar independientemente, de ser así, correríamos el riesgo de quedarnos en el paradigma dominante y fragmentario, sino que deben comprenderse como un todo, engarzados unos con otros.

La alternativa es pensar en una universidad cuya práctica sea interdisciplinaria, que permita flexibilizar toda su estructura, donde el quehacer académico adquiera supremacía. Donde, por otro lado, no solo se refuercen las áreas sustantivas como la docencia, la investigación y la acción social, sino hacer de ellas, prácticas de la cultura académica, en ese sentido deben desarrollarse todas juntas e indisolubles. Es decir, lograr que como docente pueda desempeñarse en las tres, con solvencia, pero no separadamente sino articuladas, donde se incluya también a la población estudiantil. De modo que las aulas de clase se conviertan en espacios donde se ofrezcan actividades con características de las tres áreas ya citadas, lo que redundaría también en revalorar la investigación, la acción social y la misma docencia.

De ser así, el lenguaje se transformaría promoviendo nuevas formas de comprendernos, de asumirnos, nos reivindicaríamos como sujetos que construimos diariamente el hecho educativo. También estaríamos restableciendo el diálogo permanente y dialéctico con la sociedad, respondiendo a sus necesidades.

Se debe replantear, entonces, la flexibilidad como una característica del plan de estudio, donde las docentes y los docentes puedan pensar su quehacer cara a cara con los problemas nacionales, resignificando su relación con la sociedad, donde los estudiantes de formación docente puedan y deban conocer las realidades en las cuales van a trabajar, y que puedan acercarse a la multiculturalidad y a la extranjería que se vive en los espacios áulicos, pero también que se acerquen a la marginalidad y a la desigualdad social.

Tales características exigen adoptar nuevas formas de producir y reproducir el conocimiento en la formación de formadores, que se configurarían en correspondencia con las necesidades y problemas nacionales que haya que afrontar y transformar, así como las necesidades de las políticas del Ministerio de Educación Pública, y con las posibilidades concretas -recursos humanos, materiales y simbólicos- de las facultades de Educación.

La flexibilización incluye repensar las posibilidades de transformar la formación docente con un tronco común que compartiría el estudiante y la estudiante 
de educación, luego ofrecer un ramo de unidades de aprendizaje ya sean cursos, seminarios, módulos, talleres, entre otros, que la población estudiantil pueda aprobar en forma optativa en correspondencia con sus intereses personales, académicos, sociales y laborales.

La creatividad es otra característica que debe estar presente en la formación de formadores, y requiere desterrar la pasividad en la aprehensión de los saberes, y asumir una actitud crítica, de manera que las motivaciones que posee, sean tomadas en consideración en la labor universitaria, es decir, que su realidad de juventud integre dicha labor, en un ambiente de participación, recreación y curiosidad científica. El respeto mutuo, es indispensable para que se produzca la lógica de la creatividad, de lo contrario legitimaríamos la discriminación y la extranjería. Un profesor o una profesora que permita la burla entre los estudiantes, automáticamente inhibe la manifestación original del estudiantado, y con ello impide tanto a la imaginación como a su realidad ingresar en los espacios escolares, coartando la posibilidad de reconstruir el conocimiento en forma significativa para cada estudiante, desembocando así en la transmisión vertical de saberes.

La Universidad, se ha dicho reiteradamente, es una institución que trata de buscar y construir posibilidades sociales, y es donde se crea, se recrea, se distribuye y se consume cultura, por lo que no debe sustentarse en relaciones verticales, en todo sentido, pues la relación vertical establece separaciones entre las partes. Por el contrario, la horizontalidad en las relaciones une. Así, es indispensable pensar la formación de formadores en un ambiente dialógico, de modo que las partes intervinientes en ese diálogo puedan ejercer la crítica como dinámica propia en la reconstrucción del conocimiento, y como rechazo al estacionamiento intelectual.

Llegar a asumir la dialogicidad como componente de un currículo, implica realizar cambios en la estructura simbólica de algunos profesores y profesoras, pues su quehacer lo deben replantear desde la cooperación, y no en la competitividad que estimula la exacerbación y el individualismo. Pero fundamentalmente se debe mantener y desarrollar una actitud abierta y crítica ante los cambios y a las necesidades vitales de la sociedad. Reiteramos es necesario que las vivencias, los problemas y necesidades de dichos profesores se hagan presentes en la Facultad.

¿Pero de qué manera podemos llegar a realizar lo anterior? Considero que una vía imprescindible es la permanente reflexión de la práctica pedagógica.

\section{Elementos para el cambio}

Consideramos que la investigación es la ruta que permite a la comunidad educativa reflexionar sobre sus propias prácticas y concienciar todas las formas ideológicas que la alienan. El proceso debe iniciarse con la reflexión sobre las prácticas docentes, acentuando el análisis de todos los discursos que se utilicen cuando se imparten clases, pues ellos están cargados de sentidos ideológicos. Luego se planifican las actividades académicas, en función de las modificaciones de esas prácticas alienantes, se actúa, es decir, se lleva a la acción aquello planificado y se observa la experiencia para llegar a la reflexión sobre esa observación y a partir de ese momento recomienza el nuevo ciclo de planificación.

Uno de los requisitos para que se den las condiciones adecuadas para este tipo de investigación, es que todos los integrantes y todas los integrantes de este proceso de investigación sean parte de ella, sean participantes del grupo. No descartamos la ayuda de una persona que eventualmente pueda orientar o capacitar en la temática, pero solo cuando es solicitado por las investigadoras y los investigadores. Otras personas foráneas que lleguen a coordinar, interpretar, 
observar, entre otros, con un posicionamiento directivo, limita la reflexión y niega cualquier intento emancipador, pues esta acción solo es posible si el grupo reflexiona acerca del sistema ideológico que determina sus prácticas alienadas. Un experto externo, no solo no puede lograr un nivel de aproximación a la realidad vivida, sino que en el acto de conocer, los actores sociales no logran transmitir en su totalidad su vivencia, limitando así cualquier salida del estado alienado.

Así las condiciones de su éxito estriban en el mejoramiento de las prácticas educativas reales, la mejora de los entendimientos de quienes intervienen en el proceso educativo, y la mejora de las situaciones en las cuales se desempeñan esas prácticas.

Pero toda práctica docente debe articularse con los problemas nacionales, de manera que consideramos que la permanente reflexión sobre dicha práctica nos lleva a construir un diálogo orgánico con la sociedad, que nos permita proponer cambios no solo en ella, sino en la práctica docente. De esta manera las profesionales y los profesionales que formemos, lejos de proponer acciones que atentan contra la población, buscarán formas alternativas de transformar la estructura económica, social, cultural y política, para que todos y todas tengamos acceso a un mundo mejor.

Proponer que los educadores y las educadoras se conviertan en investigadoras de sus propias prácticas, nos plantea una nueva visión acerca de lo que es la investigación, del para qué la investigación, y pone en entredicho la elaboración de saberes verdaderos, es decir, relativiza la verdad, poniéndola en la esfera de la participación en su construcción y apropiación, revalorando otros saberes que histórica y políticamente interesaba que permanecieran ocultos.

El diálogo resulta ser un camino para la reflexión, nos aproxima críticamente a la propia práctica que es donde se cristalizan los contenidos ideológicos, y nos permite elaborar cambios en la conciencia. De modo que el conocimiento del mundo, se inicia allí, con la toma de conciencia crítica acerca de la ubicación de cada uno en ese mundo.

Finalmente restablecer el diálogo, no significa establecer lazos entre dos realidades donde se obvien los sujetos; por el contrario, es la relación entre sujetos, con sus sentimientos, sus olores, sus sabores, sus colores, entre otros. Por eso el diálogo debe comenzar con un "diálogo con uno mismo" para aprehender mi lugar en el mundo, mi relación con la estructura económica, social, cultural y política donde habito.

Esta es una de las formas en que podemos reivindicar la misión de las universidades públicas, pues el deber ser de ellas, hemos dicho, es mantener un diálogo permanente con el pueblo, que es quien llena las aulas, con gustos diferentes, con costumbres, con rituales, con expectativas, con estímulos, en fin, con diferencias. A esa diferencia es la que debemos formar con una mirada crítica para reconstruir la realidad, en favor de todas las personas, luego con ellos reproduciremos la experiencia. De esta forma, como dice Paulo Freire construiremos lo inédito viable.

\section{Nota}

1. Esta situación está articulada con las políticas de contratación de docentes para que impartan lecciones. Recordemos que casi siempre se efectúa en el último momento y muchas veces cuando ha comenzado el ciclo lectivo.

\section{Referencias bibliográficas}

Anuies (s.f.) Educación Superior en el Siglo XXI. Líneas estratégicas de desarrollo. Una propuesta de Anuies, México.

Benedito, Vicenç; Virginia Ferrer y Vicent Ferreres. La formación universitaria a debate. Publicacions de la Universitat de Barcelona. 1995. 
Carr, Wilfred y Stephen Kemmis. Teoría crítica de enseñanza. La investigación-acción en la formación del profesorado. Martínez Roca. Barcelona. España. 1998.

Castells, Manuel. "Flujos, redes e identidades: una teoría crítica de la sociedad informacional". En: Castells M., Flecha, R., Freire, P., Giroux, H., Macedo, D., Willis, P. Ediciones Paidós Ibérica S.A. Barcelona. España. 1994.

Centro Nacional de Recursos para la Inclusión Educativa. "Documentos de trabajo”. San José. 2002.

Coordinación educativa y cultural centroamericana-CECC. Fraternidad. Órgano oficial informativo. No. 22. año 5. San José, Costa Rica. 2001.

Flecha, Ramón. "Las nuevas desigualdades educativas". En: Castells M., Flecha, R., Freire, P., Giroux, H., Macedo, D., Willis, P. Ediciones Paidós Ibérica S.A. Barcelona. España. 1994.

Freire, Paulo. Pedagogía de la autonomía, saberes necesarios para la práctica educativa. Siglo Veintiuno Editores, S.A. de C.V. México. 1997.

Pedagogía de la Esperanza, un reencuentro con la Pedagogía del Oprimido. Siglo Veintiuno Editores, S.A. de C.V. México. 1993.

Gorostiaga, Xavier. "Hacia una prospectiva participativa. Esquema metodológico. En: López, Francisco y Daniel Filmus (Coord.) América Latina 2000. Escenarios, alternativas, estrategias.
FLACSO. UNESCO. Temas Grupo Editorial. Argentina. 2000.

Martín-Baró, Ignacio. Haciendo la Universidad. Cuadernos universitarios FUPAC. Guatemala. 1979.

Mojica, Francisco José. "Hacia una prospectiva participativa. Esquema metodológico. En: López, Francisco y Daniel Filmus (Coord.) América Latina 2000. Escenarios, alternativas, estrategias. FLACSO. UNESCO. Temas Grupo Editorial. Argentina. 2000.

Navarrete, Lucía. "Dificultades de acceso y exclusión de estudiantes con discapacidad de la educación primaria" En: Revista Educación No. 32. Universidad de Costa Rica. 1999.

Quesada, Rolando. "Reforma curricular: rito y acto de fe" En: Revista de Ciencias Sociales No. 94. Universidad de Costa Rica. 2001.

Quesada, Rolando y Gerardo Monge. "Academia y diversidad en la Educación Superior" En: Jiménez, R. Las personas con discapacidad en la Educación Superior. Fundación Justicia y Género. 2002.

Zemelman, Hugo. Los horizontes de la razón. I Dialéctica y apropiación del presente. Colegio de México, A.C. Antropos Editorial del hombre. España. 1992a.

Los horizontes de la razón. II Uso crítico de la teoría. Colegio de México, A.C. Antropos Editorial del hombre. España. 1992b.

Rolando Quesada Sancho Docente-investigador del Instituto de Investigaciones para el Mejoramiento de la Educación Costarricense de la Universidad de Costa Rica (IIMEC) 